\title{
Correction to: Relationship between P1NP, a biochemical marker of bone turnover, and bone mineral density in patients transitioned from alendronate to romosozumab or teriparatide: a post hoc analysis of the STRUCTURE trial
}

Junichi Takada ${ }^{1} \cdot$ Rajani Dinavahi $^{2} \cdot$ Akimitsu Miyauchi $^{3} \cdot$ Etsuro Hamaya $^{4} \cdot$ Toshiyasu Hirama $^{4} \cdot$ Cesar Libanati $^{5}$. Yoichi Nakamura ${ }^{4}$ Cassandra E. Milmont ${ }^{2} \cdot$ Andreas Grauer $^{2}$

Published online: 20 March 2020

(c) The Japanese Society Bone and Mineral Research and Springer Japan KK, part of Springer Nature 2020

\section{Correction to: Journal of Bone and Mineral Metabolism https://doi.org/10.1007/s00774-019-01057-1}

In the original publication of the article, the last row of Table 1 was published incorrectly as "Serum P1NP $(\mu \mathrm{mol} / \mathrm{L})$, median $(\mathrm{IQR})^{\mathrm{b}}$ : Romosozumab, $25(18,34)$; Teriparatide, $25(20,33) "$. The correct row should be read as "Serum P1NP $(\mu \mathrm{g} / \mathrm{L})$, median $(\mathrm{IQR})^{\mathrm{b}}$ : Romosozumab, 25 $(18,34)$; Teriparatide, $25(20,33)$ ”.
In addition, the corresponding footnote for the marker ${ }^{\mathrm{b}}$ should read as "bremenopausal reference range for serum $\mathrm{P} 1 \mathrm{NP}$ is $14.9-68.8 \mu \mathrm{g} / \mathrm{L}$.

Publisher's Note Springer Nature remains neutral with regard to jurisdictional claims in published maps and institutional affiliations.

The original article can be found online at https://doi.org/10.1007/ s00774-019-01057-1.

Junichi Takada

jtakada@kitago-ortho.com

1 Kitago Orthopedic Clinic, Hokkaido, Japan

2 Amgen Inc., Thousand Oaks, CA, USA

3 Miyauchi Medical Center, Osaka, Japan

4 Amgen Astellas BioPharma K.K., Tokyo, Japan

5 UCB Pharma, Brussels, Belgium 